\title{
CINEMA, ROMANCE E VIDA COTIDIANA
}

Cinema, novel and everyday life

\section{Hidemi Soares Miyamoto ${ }^{1}$}

RESUMO: O presente artigo tem como objetivo tecer uma análise da relação entre as formas artísticas romanescas e cinematográficas e a relação que ambas estabelecem com a vida cotidiana. Para tanto, buscamos analisar a gênese dessas formas artísticas, assim como tentamos compreender as peculiaridades de cada uma delas estabelecendo possíveis aproximações e diferenças entre ambas. Concomitante a essa análise, procuramos apreender em que medida as categorias centrais acerca da vida cotidiana, de acordo com o pensamento de György Lukács, tem correspondência nas formas artísticas supracitadas.

PALAVRAS-CHAVE: Arte; Cinema; Romance; Vida Cotidiana.

ABSTRACT: This article aims to make an analysis of the relationship between novelistic and cinematic art forms and the relationship they establish with both the representation of everyday life. To this end, we analyze the genesis of these art forms as well as try to understand the peculiarities of each setting possible similarities and differences between them. Concomitant to this analysis we seek to grasp the core categories that characterize everyday life according to the thought of György Lukács.

KEYWORDS: Art, Movie; Novel; Everyday Life.

\section{INTRODUÇÃO}

O surgimento da arte cinematográfica só se tornou possível quando o modo de produção capitalista atingiu certo nível de desenvolvimento técnico que provocou um maior grau de dependência ao grande em comparação a outras expressões artísticas.

Não se trata de um exagero quando se afirma que o cinema é a expressão artística mais condizente com as profundas transformações que ocorreram entre o século XIX e o século XX, que posteriormente buscarei explicar. Tanto do ponto de vista da capacidade que a arte fílmica tem de representar o mundo em movimento como do ponto de vista que ele tem de ser uma obra de arte que está em estreita consonância com as transformações corpóreas e sensoriais

\footnotetext{
${ }^{1}$ Mestre e Doutorando em Sociologia pela Universidade Federal da Bahia. Email: hidemi.soares@hotmail.com
} 
provocadas pelo desenvolvimento do capitalismo. Então, a existência desta dependência entre cinema e capitalismo pode ter como consequência uma forte influência de determinações extraestéticas nos conteúdos fílmicos. Esta possibilidade é consequência da dupla mimesis peculiar ao cinema, trataremos mais detalhadamente deste conceito mais adiante, pois, as imagens fílmicas se caracterizam por produzir uma impressão de autenticidade, discutiremos mais adiante também este conceito, em que nenhuma outra forma artística é capaz.

No romance o processo criativo e de refiguração da realidade centra-se no próprio escritor. Dessa forma, diferentemente do cinema a representação da vida cotidiana não se caracteriza por esta impressão de autenticidade, portanto, o processo mimético é de natureza diversa ao do cinema. O efeito estética produzido pelo romance se dá mediado pela palavra já no cinema é fundamentalmente visual. Consequentemente a reconstrução estética da vida tem como centro dramático os destinos, paixões, dores e aspirações humanas e a realidade objetiva torna-se secundária. No cinema, a representação dramática da vida humana se encontra em um mesmo patamar que os objetos da natureza o que produz uma relação mais próxima entre a vida cotidiana e a refiguração artística que se não encontra na forma romanesca.

\section{CINEMA, ROMANCE E CAPITALISMO. A VIDA COTIDIANA CONQUISTA DEFINITIVAMENTE A ARTE.}

Aparentemente, o cinema e a forma romanesca não apresentariam maiores semelhanças entre si além, é claro, do fato que ambos são formas de arte. Soma-se a isso o fato do cinema ser uma arte fundamentalmente visual e a forma romanesca se utilizar da linguagem escrita para produzir efeitos estéticos. No entanto, analisando a gênese dessas duas expressões de arte encontramos algumas importantes similitudes. A primeira semelhança não está relacionada com os elementos estritamente estéticos, mas sim com o período histórico que essas duas manifestações artísticas surgiram, de modo que ambas só puderam se desenvolver com o advento da moderna sociedade capitalista.

Tanto o cinema quanto o romance foram duas formas de arte que expressaram os novos conteúdos sociais que surgiram com o advento do capitalismo, seja pelo desenvolvimento exacerbado da esfera do indivíduo em contraposição a coletividade, como também pelo recrudescimento de um grande mercado consumidor que possibilitou, por sua vez, o surgimento de uma cultura de massa. No que se refere à literatura, essas mudanças proporcionadas pelo desenvolvimento do capitalismo acarretaram no desaparecimento de uma determinada forma 
literária, a saber, as epopeias, proporcionando o surgimento da forma romanesca.

Segundo Lukács (2000), a natureza estrutural do romance gira em torno de uma oposição entre o herói problemático e o mundo degradado, que diferentemente das epopeias antigas - em que o herói dava vazão a valores comunais -, trata-se de dar voz a valores individuais. Do ponto de vista do conteúdo narrativo, o romance se caracteriza por uma democratização na representação dos atores sociais e dos conflitos sociais.

É, por isso, que Miguel de Cervantes é considerado o criador desse novo gênero literário, pois, ele conseguiu mesclar elementos da narrativa medieval a exemplo da aventura dos cavaleiros medievais, combinada à representação fidedigna das classes subalternas que emergiam no processo histórico. O conteúdo do romance é mais democrático em sua representação da realidade. Dessa forma,

Mas o novo material, cuja apropriação artística levou à criação da nova forma romanesca, não nasceu apenas desta renovação democrática da temática de aventuras da velha narrativa, ora aproximada à vida real: é agora a prosa da vida que, ao mesmo tempo ingressa no romance moderno. Cervantes e Rabelais, criadores do romance moderno, refletem em suas obras este importantíssimo fato, ainda que dele extraiam conclusões diferentes. Tanto a aristocracia de Cervantes quanto o burguês de Rabelais se rebelam, por um lado, contra a degradação do homem na moribunda sociedade feudal, e, por outro, contra a degradação na nascente sociedade burguesa, embora cada um deles veja a seu modo o caminho para superar essa dupla degradação. (Lukács, 2009, pg. 213).

Além disso, tanto nas epopeias gregas como na narrativa medieval havia uma representação simbiótica entre os seres humanos e as divindades, diferentemente da forma romanesca que abre espaço para a refiguração de um universo social sem Deus. Exemplifiquemos essa diferença entre o herói da Ilíada, Aquiles, e um herói de um romance moderno como Oskar Matzerath de $O$ Tambor. O primeiro tinha a proteção dos deuses da Grécia Antiga em sua caminhada, já o segundo é o produto de um mundo sem Deus e que deve encontrar o seu sentido à vida de forma solitária.

Para a arte narrativa da idade média existe semelhante proximidade entre a ordem religiosa cristã e realidade terrena, de forma que só permite que esses personagens se tornem verdadeiros heróis por terem Deus a seu lado. Segundo Varandas (2010), os heróis medievais se orientam de acordo com um código de valores cristãos e tem como figura ideal Jesus Cristo. O herói-cavaleiro internaliza as virtudes morais e espirituais da religião cristã tendo como objetivo se aproximar o mais possível do cavaleiro perfeito, que era Jesus. Pois,

O cavaleiro age assim em prol de Cristo contra os inimigos de Deus e, como tal, simboliza o Bem que, a toda hora, se confronta com o Mal de modo a fortalecer a Fé e permanecer no trilho da salvação. Daí que seja a figura central 
da psicomaquia que, alegoricamente, representa, mais do que a luta entre a virtude e os vícios, a batalha da alma contra o Mal. (Varandas, 2010, pg.36).

De modo geral, essa proximidade entre religião e realidade tinha como efeito estético um tipo de refiguração que transcendia a trivialidade da vida cotidiana. Dessa forma, os elementos extraordinários refigurados esteticamente tinham como objetivo enaltecer essas potências divinas, tornando possível à construção de heróis positivos. Os heróis das epopeias gregas e das narrativas medievais davam vazão aos valores comunais ou, dito de outra forma, esses heróis representariam determinados valores de uma sociedade.

O inverso ocorre no romance, pois com o advento da modernidade burguesa que se admitia um mundo sem Deus, não há mais a possibilidade de se representar esteticamente uma realidade permeada de feitos extraordinários patrocinados pelas divindades gregas, ou cristãs, como também não há mais a proximidade entre os deuses e os homens. Para Lukács (2009), o romancista se volta para a representação da vida cotidiana burguesa, na medida em que almeja tornar-se o historiador da vida cotidiana burguesa Daí a proximidade entre o realismo e a forma romanesca. Portanto, nesse processo de reconstrução estética é possibilitado ao romancista refigurar todas as contradições sociais advindas com o desenvolvimento do modo de produção capitalista.

\subsection{AS DETERMINAÇÕES DA VIDA COTIDIANA.}

Dessa peculiaridade do romance, em democratizar seus conteúdos estéticos representando a vida cotidiana burguesa, Lukács apresenta três características fundamentais da vida cotidiana: a imediaticidade, a heterogeneidade e a superficialidade extensiva. O conhecimento advindo da vida cotidiana é fundamentalmente operativo, imediato, sendo basicamente funcional às atividades práticas. Esse tipo de conhecimento tem por objetivo que o indivíduo resolva os problemas postos pela vida cotidiana de forma imediata.

A superficialidade extensiva da vida cotidiana relaciona-se de forma direta com o conceito de heterogeneidade, pois a primeira busca dar respostas a problemas postos por essa heterogeneidade da vida cotidiana sem, contudo, levar em consideração as relações e conexões existentes entre os fenômenos. Em suma, na cotidianidade temos que resolver múltiplos problemas para conservar nossa própria existência. Quando se trata da heterogeneidade, porém, as respostas que nós damos a essas questões não se caracterizaram por uma objetividade científica, apenas bastaria que fossem funcionais e operativas.

E dada essa heterogeneidade da vida cotidiana seria perfeitamente natural que existissem formas simultâneas de concepções de mundo que pudessem se caracterizar por serem totalmente 
contraditórias entre si. Porém, essa contraditoriedade no nível do cotidiano não pode ser problematizada, ou se for, estaríamos em outro patamar de objetivação humana como a ciência ou a arte. Consequentemente, adentrar a essencialidade dos fenômenos sociais, suas determinações e relações recíprocas, se encontra de forma nebulosa no pensamento cotidiano.

No cotidiano há, portanto, uma tendência a ficar obscurecida a gênese e a causalidade dos processos sociais, de modo que a crescente complexidade da vida no capitalismo favorece a construção de explicações contraditórias para os fenômenos sociais. O objetivo mais importante que o "homem inteiro" da cotidianidade busca sempre aquilo que lhe útil e que lhe é prático, inclusive no que se refere às atividades mentais. Ocorre como consequência disso na moderna sociedade burguesa uma não problematização das repostas que os indivíduos têm que dar aos problemas que são postos pelo dia a dia. A gênese social dos fenômenos se encontra escamoteadas abrindo espaço a respostas individuais a problemas eminentemente sociais.

Com o desenvolvimento das estruturas sociais há uma crescente complexificação da vida cotidiana. Dessa forma, surgem novos problemas que os indivíduos singulares são obrigados a solucionar com a superação desse tipo de conhecimento heterogêneo e superficial. Os indivíduos sociais são obrigados a apreender as conexões causais de problemas mais complexos, possibilitando o surgimento de uma forma superior de objetivação humana, no caso a ciência.

A vida cotidiana pelo entendimento de Lukács não pode ser de forma alguma o espaço da alienação, da inautenticidade, determinações essas historicamente constituídas. Contrariamente a isso ele argumenta que em alguns casos pode haver o caminho inverso, na medida em que às relações cotidianas exerçam pressões sobre questões da ciência que já não respondem às necessidades sociais.

Si nos representamos la cotidianidad como um gran rio, puede decirse que del él se despreden, en formas superiores de recepción y reproducción de la realidad, la ciencia y el arte, se diferencian, se constituyen de acuerdo com sus finalidades especificas, alcanzan su forma pura em esa especificidad- que nace de las necesidades da vida social- para luego, a consecuencia de sus efectos, de su influencia en la vida de lós ombres, desembocar de nuevo em la corriente de la vida cotidiana. (Lukács, 1982, pp. 11-12).

Ponto importante também a ser observado é que na esfera do cotidiano a própria vida aparece como algo que não apresenta nenhum sentido, ou nenhum tipo de conexão. A compreensão dela seria mediada por perspectivas transcendentais e, posteriormente, também pela ciência. Ademais, para esse "homem inteiro" da vida cotidiana as construções sociais aparecem como se não possuíssem uma gênese histórica. O que se constitui historicamente passe a ser percebido como sendo algo natural.

Essa característica da imediaticidade que nos referimos mais acima tem sua expressividade 
no que Lukács chama de materialismo espontâneo. Esse tipo de materialismo se encontra estritamente vinculado com o trabalho, ou melhor, tem sua gênese no ato laborativo, pois, para o sucesso de todo ato de trabalho se faz necessário além do pôr teleológico, a apreensão correta de toda a rede causal do objeto. A consciência trata essa trama causal como tendo uma existência que independe de sua própria consciência.

Para Lukács (1982), a força desse materialismo espontâneo está justamente na proeminência da realidade sobre quaisquer tipos de concepções idealistas de mundo. Nesse caso, a esfera ontológica terá a primazia sobre quaisquer tipos de representação sobre o mundo. E a fraqueza desse tipo de materialismo reside justamente pela pouca influência que exerce sobre tais concepções de mundo, ou seja, esse tipo de materialismo não teria a força argumentativa, por exemplo, do discurso científico, para que houvesse um questionamento sobre as visões de mundo de cunho religioso.

Apesar de todo o desenvolvimento da ciência e o consequente enriquecimento da vida cotidiana por meio dessa objetivação, o caráter imediatista da vida cotidiana nunca poderá ser ultrapassado. Isto se dá pelo simples fato de que se a cada ato cotidiano tivéssemos que necessariamente pensar de forma reflexiva, como ocorre na ciência, à reprodução social se paralisaria. Nesse caso a vida cotidiana seria, portanto, insuprimível.

Especificamente na moderna sociedade burguesa que se fundamenta na relação contraditória entre capital e trabalho assalariado, o cotidiano nesse tipo de sociedade é marcado pelo imperativo da produção e as ações dos indivíduos na cotidianidade têm de dar respostas às necessidades advindas da esfera da produção e do consumo.

Visto assim, os homens do cotidiano passam a orientar seus comportamentos tendo como base as necessidades da acumulação do capital. A sociabilidade burguesa tem por fundamento a busca incessante pelo lucro em detrimento das necessidades sociais. Então, tal forma de organização do cotidiano nesse período histórico em particular faz com que o caráter imediato dessa práxis seja predominantemente dominado pelo utilitarismo econômico.

Contrariamente a essas determinações da vida cotidiana, a ciência e, em especial, a arte buscam transcender essa beterogeneidade produzindo cada uma a sua maneira um mundo homogêneo. Há um esforço por parte do artista em afastar, eliminar tudo o que é supérfluo e heterogêneo ao universo criado esteticamente. Aquilo que no nível da vida cotidiana aparentemente não apresenta nenhum tipo de relação, no universo artístico essa descontinuidade é superada em direção a uma continuidade, os fenômenos sociais passam a se relacionar entre si mediados pela subjetividade criativa do artista. No processo de recepção artística, o indivíduo se depara com um mundo homogêneo dotado de sentido que proporciona a superação da singularidade da vida cotidiana, 
proporcionando o contato do indivíduo com o gênero humano, ou com a universalidade. Segundo Frederico (2013), a arte para Lukács educa os homens.

A arte, portanto, educa o homem fazendo-o transcender a fragmentação produzida pelo fetichismo da sociedade mercantil. Nascida para refletir sobre a vida cotidiana dos homens, a arte produz um "elevação" que a separa inicialmente do cotidiano para, no final, fazer a operação de retorno. Esse processo circular produz um contínuo enriquecimento espiritual da humanidade. (Frederico, 2013, p. 135).

Lukács (1982) considera a arte e a ciência como formas de consciência pura, ou seja, dotadas de uma autonomia, pois se orientam por explicar o mundo tendo o homem como centro sem nenhum tipo de apelo a entidades transcendentais, religiosas. Bem como a consciência pura que não está relacionada a nenhum tipo de idealismo filosófico, apenas pela necessidade dessas formas de objetivação transcenderem à própria beterogeneidade da vida cotidiana.

\subsection{ARTE E ANTROPOMORFIZAÇÃO}

Assim sendo, a diferença existente entre os complexos da ciência e da arte estão na forma como refletem a realidade objetiva, de forma que a ciência é essencialmente desantropormofizadora, ao passo que arte produz um universo antropomorfizante.

Como já foi exposto anteriormente, em determinado momento histórico essa relação imediata entre teoria e prática mediada pelo materialismo espontâneo não mais consegue dar respostas aos problemas da vida. Estamos diante da gênese do pensamento científico, o qual, além de se caracterizar pelo caráter de universalidade, necessita também de comportamento reflexivo. O sujeito do conhecimento deve se submeter totalmente à legalidade do próprio objeto tentando apreender as leis causais que regem o fenômeno conforme depura quaisquer traços de subjetividade. Por isso a ciência apresenta esse caráter desentropormofizador. Tal discussão sobre o conceito de desantropomorfizaçãa será importante, pois, o cinema nessa perspectiva transita entre o elemento desantropomorfizante e antropomorfizante, sendo este último o que caracterizaria as formas de arte em geral.

Ao lado dessa necessidade posta pela reprodução social temos também a necessidade do homem produzir um tipo de objetivação em que a riqueza de seu universo subjetivo esteja no centro dessa criação. Para Tertulian (2003), o móvel de toda obra de arte seria a "autocontemplação da subjetividade". No caso da ciência a centralidade do reflexo se encontra no objeto, enquanto na arte o centro é a própria interioridade humana, mesmo que para Lukács uma subjetividade enriquecida seja indissociável de um conhecimento do mundo objetivo. Assim sendo, 
Isto não foi um acaso. Os fundamentos sociais e psicológicos do classicismo alemão foram o resultado da Revolução francesa e da nova situação mundial por ela criada. Ora, esta situação só favoreceu o desenvolvimento do classicismo no lapso de tempo em que os escritores alemães puderam observar como espectadores não engajados. Da mesma forma, o surgimento do grande realismo da primeira metade do século XIX data somente do instante em que os escritores podem lançar um olhar histórico retrospectivo ao período revolucionário já terminado (Walter Scott, Balzac, Stendhal). (Lukács, 1965, pp. 165-166).

Nesse sentido, o processo de antropormofização do mundo buscaria “"...] restaurar teleologicamente o mundo para sua própria condição humana, para situar a totalidade dos fenômenos e experiências com relação a seus próprios impulsos e aspirações" (Tertulian, 2003, pg.207). Vemos então que na arte e na religião são construídos universos simbólicos que buscam dar algum sentido a existência humana,de modo que a arte autêntica ainda possibilita o enriquecimento da humanidade, ao contrário da religião que busca responder aos problemas humanos em entes transcendentais.

\subsection{A REALIDADE PROSAICA NO CINEMA E NO ROMANCE}

É essa realidade prosaica, da vida cotidiana, que se torna objeto estético tanto para a forma romanesca quanto para o cinema. No romance, tendo em vista que a modernidade capitalista se caracteriza por ser um mundo abandonado por Deus, não há mais a necessidade de se representar fatos extraordinários que sofrem a influência direta das divindades. Ainda segundo Lukács (2009), o romancista se volta para a representação da vida privada burguesa tentando tornar-se o historiador da vida cotidiana burguesa. Portanto, nesse processo de reconstrução estética é possibilitado ao romancista refigurar todas as contradições sociais advindas com o desenvolvimento do modo de produção capitalista.

Dessa forma, o romance moderno enquanto produto de uma estrutura social que desenvolve de forma bastante intensa o individualismo humano, apresenta um herói que não pode mais ser o porta voz de valores comunais. Há uma ruptura entre o herói do romance e o mundo que o circunda, de modo que os valores desse herói não pode ser mais exemplo de conduta para ninguém. Lukács (2000) cunhou o conceito de herói problemático para definir esse tipo de personagem que se encontra em um processo de ruptura com o mundo em que vive.

O herói problemático é um tipo de personagem que ao mesmo tempo em que compartilha dos valores dessa nova sociedade que surgia, é extremamente crítico desses valores, pois já acredita que os valores capitalistas não apresentam nenhum tipo de positividade. É nessa contradição dialética que o herói romanesco vive.

Então é nessa nova estrutura social onde surge o romance e o cinema, que primeiramente 
se caracterizam por um forte pendor ao realismo. E, nesse sentido, o realismo deve ser entendido mais como um método de composição artística do que como uma determinada escola estética singular. Como, por exemplo, o realismo literário europeu que permeou os séculos XVIII e XIX tendo como expoentes Victor Hugo (1802-1885), Honoré de Balzac (1799-1850) e Tolstói (18281910).

Para entendermos a forma como ocorre a proximidade entre a arte cinematográfico e a vida cotidiana devemos partir do conceito de dupla mimesis de Lukács. O cinema, para ele, apresenta sua singularidade no fato de que há dois momentos na criação da obra fílmica. $\mathrm{O}$ primeiro deles é a captação da imagem em si e o segundo momento ocorre na esfera da edição e montagem das cenas que foram captadas neste primeiro momento, esta discussão se aproxima da análise de Benjamin (1996), pois, para este autor a filmagem de cada cena se dá de forma fragmentária e que a organização em uma totalidade só pode ocorrer no momento da edição e da montagem, isto ocorre porque a câmera cinematográfica tem a capacidade de captar os objetos e as ações humanas de forma desantropomorfizadora e o processo de seleção, hierarquização e combinação das imagens só pode ocorrer nesse segundo momento.

E, a proximidade que se encontra a refiguração da vida cotidiana e do cinema reside fundamentalmente na capacidade que esta arte tem em captar o decurso real do tempo, portanto, uma consequência do próprio desenvolvimento técnico que caracteriza esta arte. A objetiva cinematográfica possibilita ao cineasta apreender o movimento do mundo, da forma como experimentos a temporalidade na própria realidade objetiva e das relações entre os seres humanas e os objetos que se encontram ao seu redor. Então, esta capacidade desantropormofizadora da objetiva proporciona aos espectadores uma impressão de autenticidade. Para Lukács é em consequência desta impressão de autenticidade a responsável pela afinidade existente entre a refiguração da vida cotidiana e da arte cinematográfica. Segundo Lívia Cotrim (2013)

Nesse ponto Lukács identifica outra especificidade do filme: este inclui de modo muito mais amplo o entorno social e natural do homem, mas o faz "não a partir do homem como centro, mas sim exatamente como costuma aparecer de fato, como é percebido pelo homem do cotidiano: como intercâmbio entre muitos fatores igualmente reais". É o que abre ao filme as mais amplas possibilidades para figurar de modo autônomo seres que, em outras formas artísticas, só podem ser plasmados em sua relação com o homem enquanto centro configurativo. (Cotrim, 2003, p. 58).

\subsection{O CINEMA ENTRE A ANTROPOMORFIZAÇÃO $\quad$ E A DESANTROPOMORFIZAÇÃO}


Já Walter Benjamin (1996) centra sua análise principalmente na relação entre o desenvolvimento das forças produtivas e o surgimento dessa nova manifestação de arte: o cinema. Além disso, insere outra discussão importante que seria a relação existente entre o cinema e as transformações pelas quais passaram as dimensões sensoriais e subjetivas do homem nessa modernidade capitalista.

Essa relação que Benjamin faz entre o cinema, as novas formas de sociabilidades engendradas pelo capitalismo e as mudanças na percepção e na subjetividade humana é convergente à tese de Marx (2010) sobre o caráter eminentemente histórico da estética e dos sentidos humanos. É a partir de um determinado período histórico que os sentidos humanos se desenvolvem nessa direção, e sobre a importância do trabalho para esse desenvolvimento e para as suas futuras transformações.

Compreende-se que o olho humano frui de forma diversa da que o olho rude, não humano [frui]; o ouvido humano diferentemente da do ouvido rude etc. [...] Por outro lado, subjetivamente apreendido: assim como a música desperta primeiramente o sentido musical do homem, assim como para o ouvido não musical a mais bela música não tem nenhum sentido, é nenhum objeto, porque o meu objeto só pode ser a confirmação de uma das minhas forças essenciais, portanto só pode ser para mim da maneira como a minha força essencial é para si como capacidade subjetiva [...] vai precisamente tão longe quanto vai o meu sentido, por causa disso é que os sentidos do homem social são sentidos outros que não os do não social [...]. (Marx, 2010, pp. 109 e 110).

Na sua análise, Benjamin (1987) realiza um percurso histórico que vai da Grécia Antiga até início do século XX, com o objetivo compreender o complexo processo de autonomização das formas artísticas em relação à religião, bem como compreender o concomitante processo de democratização da arte que culminou com o cinema.

A arte fílmica seria a mais democrática do ponto de vista da recepção, pois em se tratando de um ramo industrial qualquer, o cinema em sua imanência necessita da existência de um grande mercado consumidor para que possa continuar existindo.

Essa mudança na percepção humana desse período histórico que viu florescer o cinema estaria estritamente vinculada com o aparecimento das grandes massas no cenário político e social. O surgimento das grandes metrópoles, as mudanças no aparelho sensorial humano devido às novas formas de relações no trabalho, a intensificação do tráfego nessas cidades e o estímulo ao consumo via desenvolvimento da publicidade são todos elementos que explicariam tais transformações. Segundo Ben Singer (2004), esse período histórico caracterizar-se-ia por ser um momento no qual as experiências fenomênicas seriam mais caóticas, mais rápidas e mais fragmentárias do que em formações sociais de outros períodos históricos. É, nesse sentido, que afirmamos mais acima sobre as mudanças sensoriais e corpóreas pela qual passou a humanidade 
com o advento da modernidade capitalista.

As grandes cidades que se desenvolveram a partir do século XIX eram espaços que sujeitavam seus habitantes a uma vida cotidiana bastante frenética. Esse novo estilo de vida sofria a influência do desenvolvimento dos meios de transporte que seriam cada vez mais velozes, sobretudo nas grandes metrópoles subordinadas à utilização do tempo imposta pelo capitalismo avançado. Dessa forma, emergem todos esses elementos da modernidade, que tem sua gênese na forma como se estabelecem as relações hierárquicas do trabalho no capitalismo, e como essas relações alteram o modo como nós vivenciamos o tempo, e a própria vida em sua totalidade, de forma mais rápida.

O tempo na esfera da produção passa a ser cronometrado e controlado. Portanto, essas transformações nas bases materiais possibilitaram a transformação dos alicerces tanto psicológicos quanto fisiológicos da experiência subjetiva. Só para termos ideia dessas intensas transformações, Ben Singer (2004) afirma que entre os anos de 1870 e 1910 a população dos grandes aglomerados urbanos dos EUA quadruplicou de tamanho.

O caos da cidade instalou na vida um flanco nervoso, uma sensação palpável de exposição ao perigo. Como mencionou o editor da Outlook em 1900, "O espectador não está excessivamente receoso, mas ele confessa que nesses dias de afobação quase sempre fica um pouco nervoso nas ruas da cidade com receio de que alguma coisa possa acontecer a alguém”. A cidade moderna parece ter transformado a experiência subjetiva não apenas quanto a seu impacto visual e auditivo, mas também quanto as suas tensões viscerais e suas cargas de ansiedade. (Singer in Charney e Schwartz, pp. 106).

Complementar a essa discussão, a análise de Margaret Cohen (2004) se fundamenta no fato de que desde as primeiras obras cinematográficas de Thomas Edison e dos irmãos Lumière, o cinema tem uma relação bastante intensa com a representação da vida cotidiana. O cotidiano é entendido pela autora como o espaço da produção e reprodução das pessoas que se delineiam pela lógica da produção capitalista da mais-valia e da crescente industrialização, da urbanização, da atomização e da abstração da vida social nessa sociedade burguesa.

Ainda, segundo a autora, foi com o advento da modernidade capitalista que a vida cotidiana passou a ter o status de ser um objeto válido da análise científica e, além disso, a cotidianidade passou a ser objeto de atenção representacional, propiciando com que fosse possível o surgimento de novos gêneros de representação, como o cinema e o romance.

Nesse sentido, merece destaque a chamada literatura panorâmica que buscava representar justamente a trivialidade da vida comum burguesa e suas incessantes transformações fazendo com que houvesse uma aproximação desse tipo de literatura que visava o entretenimento com a forma romanesca e o cinema. 
Passemos agora para a relação muito importante entre a fotografia e o cinema, pois, a criação da fotografia faz com que ocorra um salto qualitativo na representação da vida cotidiana, pois possibilita a captação do em-si dos objetos. A câmera fotográfica e a de cinema conseguem captar os objetos tal como eles são em sua existência independente da consciência humana. Portanto, a fotografia, e, posteriormente, o cinema apresenta uma característica importante em comum, pois, em ambas não há possibilidade de se duvidar sobre a realidade dos objetos refigurados. Sendo assim, a categoria da autenticidade é central nessas duas formas de arte. A relação entre vida cotidiana e essas duas expressões artísticas é mais direta. É essa capacidade da câmera de captar o em-si dos objetos que faria com que o cinema transitasse entre a desantropomorfiæação e a antropomorfização em sua refiguração do mundo.

A categoria da autenticidade no cinema se refere ao fato de que a realidade que se encontra representada em uma dada obra possui uma existência material independente da consciência humana. Um determinado copo que se encontra filmado em uma cena tem uma corporeidade que a câmera diretamente não consegue transformá-lo em uma cadeira, por exemplo. Essa é a relação entre a autenticidade um tipo de cinema de natureza realista.

Essa proximidade do cinema com a vida cotidiana tem como consequência uma refiguração naturalista da realidade que em outras formas de arte seria anti-artístico. Pois, a reconciliação dos homens e dos objetos que o cinema consegue representar através da captação do curso real do tempo é extremamente negativo quando se comparado, por exemplo, com a forma romanesca. No romance há uma necessidade tão grande de se centrar a construção da narrativa nos dramas, nos sentimentos, no destino dos homens que a refiguração dos objetos, do mundo exterior, se torna tão somente uma descrição secundária.

Isto significa que tanto os homens como o mundo aparecem no cinema com igual valor de realidade. O homem no cinema não aparece no centro da refiguração estética como ocorre com outras expressões artísticas, aparecendo como um produto da interação de diversos fatores com o mesmo peso de realidade.

Nesse sentido, devemos observar a necessidade formal da existência do narrador na arte épica, e no romance, e o fato de que no cinema não existe essa necessidade. Tal diferença entre essas duas manifestações de arte reside no tipo de linguagem que as caracterizam $\mathrm{O}$ cinema por produzir seus efeitos estéticos mediante a utilização da imagem não necessita da existência de um narrador que construa as relações ocorridas na trama fílmica; dessa forma a utilização da montagem torna-se um expediente de extrema importância para o cineasta provocar reações nos espectadores sem a necessidade de se utilizar a linguagem escrita.

Já para o romance não há tal possibilidade. As relações entre os homens e os objetos 
necessitam da existência do narrador para que se tornem inteligíveis aos leitores e que não sejam tão somente um amontoado de informações desconexas entre si. Daí a importância da narração, pois ela relaciona os acontecimentos do romance entre si, produzindo uma organicidade e um efeito estético.

\section{CONSIDERAÇÕES FINAIS}

Objetivamos neste artigo analisar a intrínseca relação existente entre as formas artística do cinema e do romance moderno. Tal relação entre duas formas de aparentemente tão díspares entre si, pois, uma se objetiva através da linguagem escrita e a outra através da linguagem audiovisual, ambas tiveram sua gênese histórica com o advento da sociabilidade burguesa. Procuramos demonstrar que essas formas de arte se caracterizam por buscar representar as relações cotidianas que se estabeleceram no capitalismo, bem como analisamos as determinações categoriais mais importantes que caracterizam a vida cotidiana, dentro da perspectiva de Lukács.

Para tanto analisamos as peculiaridades e aproximações que encontramos na forma romanesca e na arte fílmica. Se, em relação ao conteúdo as duas formas de arte apresentam uma semelhança, pois, ambas buscam representar a vida cotidiana que emergiu a partir da modernidade capitalista e sua consequente relação entre o indivíduo e a sociedade, do ponto de vista das diferenças formais as abordamos através das peculiaridades miméticas inerentes a essas duas expressões artísticas.

No romance o processo mimético se encontra centrado na figura do escritor e, portanto, é mediada pela subjetividade crítica do escritor que fornece o efeito estético de um determinado romance. No cinema o diretor deve trabalhar sobre uma realidade preexistente, ou seja, a dupla mimenis significa que primeiramente há a captação de imagens desconexas e fragmentárias e no segundo momento, o da edição e da montagem, é que existe o processo de seleção, organização e hierarquização que visa produzir a obra de arte.

Portanto, o cinema e o romance são duas expressões de arte de suma importância para que possamos compreender o momento histórico em que vivemos, pois, ambas buscam fundamentalmente representar as relações cotidianas que surgiram com o advento da modernidade capitalista. 


\section{REFERÊNCIAS:}

BENJAMIN, Walter. Magia e Técnica, arte e politica: ensaios sobre literatura e história da cultura: Obras Escolbidas, vol. I. São Paulo: Brasiliense, 1996.

CHARNEY, Leo, SCHARTZ, Leo (Orgs). O Cinema a invenção da vida moderna. São Paulo: Ed Cosac Naif, 2004.

COTRIM, Lívia. Apresentação de "Lukács e o Cinema. In: Chagas, Rodrigo. (Org.). Cinema, Educação e Arte. 1ed.Boa Vista: Editora da UFRR, 2013, v. 1, p. 51-75.

COSTA, Lúcia Cortes. A estrutura da vida cotidiana: uma abordagem através do pensamento luckasiano. Disponível em

http://www.revistas2.uepg.br/index.php/emancipacao/article/viewArticle/22> Acesso em: 10 nov. 2013.

LUKÁCS, György. Estética. Vol. I, Grijalbo, 1982. Estética. Vol. IV, Grijalbo, 1982. Arte e Sociedade: Escritos estético 1932-1967. Rio de Janeiro: Editora UFRJ, 2011. . A teoria do romance. São Paulo: Duas Cidades; Editora 34, 2000. Ensaios de literatura. Rio de Janeiro: Editora Civilização Brasileira, 1965.

MARX, Karl. Manuscritos econômico-filosóficos. São Paulo: Boitempo Editorial, 2010.

TERTULIAN, Nicolas. Georg Lukács: Etapas de seu pensamento estético. São Paulo: Editora Unesp, 2008.

VARANDA, Angélica. O rosto do herói medieval: Beowulf e Gawain. Disponível em < http://ppg.revistas.uema.br/index.php/brathair/article/viewFile/450/389> Acesso em 13 Jan. 2014. 